\title{
Exploring Impulse Buying in Services: Toward an Integrative Framework
}

\begin{abstract}
Prior research on impulse buying focuses mostly on goods, ignoring its incidence in services despite growing evidence about the prevalence of impulsive behaviors across diverse consumption contexts. This paper introduces an integrative conceptual framework to study impulse buying in both goods and services by using perceived risk as a focal construct in the impulse buying process and reports findings from two empirical studies. The first study uses a mall-intercept survey to show that perceived risk is lower and likelihood of impulse buying is greater for services with higher tangible (vs. intangible) attributes and higher search (vs. experience and credence) properties. The second study uses a lab-experiment to show significant differences in the influence of three relevant consumer traits (consumer impulsiveness, optimum stimulation level, and self-monitoring) on the level of perceived risk and impulsiveness in purchase decisions for six different services with varying levels of attributes (tangible vs. intangible) and evaluation properties (search, experience, and credence). Overall, the two studies provide substantial evidence of the presence of impulse buying in services and useful insights for researchers and services marketers.
\end{abstract}

Keywords: Consumer impulsiveness; credence; experience; impulse buying; intangible; optimum stimulation level; search; self-monitoring; tangible 


\section{Introduction}

Impulse buying is a popular topic in marketing, but prior research mostly focuses on impulse purchase of goods and seems to ignore impulse buying of services irrespective of the retail formats studied, including supermarkets (Peck and Childers 2006), departmental stores (Kwon and Armstrong 2002), shopping malls (Beatty and Ferrell 1998; Jones, Reynolds, Weun and Beatty 2003; Rook and Fisher 1995), and airport shops (Crawford and Melewar 2003; Omar and Kent 2001). Even studies on impulse buying in interactive channels (e.g., television and Internet) focus on goods, such as music CDs (Adelaar, Chang, Lancendorfer, Lee and Morimoto 2003), clothes, cosmetics, shoes, books, toys, car accessories, computer hardware, sports equipment (Madhavaram and Laverie 2004), and household/sporting goods (Jeffrey and Hodge 2007; Kukar-Kinney, Ridgway and Monroe 2009; Park and Lennon 2006).

Most qualitative studies also report impulse buying only in goods, including candy, magazines, ice cream, clothes, jewelry, paintings (Rook 1987); food, shoes, cars, houses (Bayley and Nancarrow 1998); books, watches, and purses (Hausman 2000), with no evidence of impulse buying in services. Similarly, studies outside the U.S. also explore impulse buying mostly in goods such as personal accessories in Vietnam (Nguyen, Jung, Lantz and Loeb 2003), supermarkets in China (Zhou and Wong 2003) and India (Mohan, Sivakumaran and Sharma 2013), and shopping malls in Singapore (Sharma, Sivakumaran and Marshall 2010a, b), South Korea (Kwak, Zinkhan, DeLorme and Larsen 2006) and Taiwan (Lin and Lin 2005).

As seen above, prior research on impulse buying around the world has focused mostly on goods despite the growing importance of a wide variety of services touching every aspect of a modern consumer's life, ranging from entertainment, health care, banking, insurance, travel, and restaurants to mobile phone and Internet service. In fact, the service sector dominates the 
developed economies, accounting for $75-80 \%$ of their GDP; even in the developing economies, the service sector accounts for 50-60\% of output (Lovelock, Wirtz and Chatterjee 2012, pp.6-7). Hence, it is important to investigate if consumers indulge in impulse buying in services, to explore the characteristics of services related to varying levels of impulse buying, and to uncover systematic reasons for some services being associated with greater impulse buying than others.

A few studies that do explore impulse buying in services, such as paid subscriptions to financial reports and stock market quotes (Phau and Poon 2000), frontline service employees' role as a trigger for impulse buying in banking services (Agrawal and Schmidt 2003), and impulse-induced mobile shopping (Chiang and Liao 2004), are mostly descriptive and do not provide any significant theoretical insights about how the process of impulse buying in services may be different compared to that in goods. We address this gap by seeking answers to the following specific research questions:

1. Do consumers buy services impulsively? If yes, then which types of services are more likely to experience impulse buying?

2. What are the similarities and differences in the process of impulse buying for different types of services based on service attributes and evaluation properties?

To address these questions, we first reviewed the impulse buying literature to identify a framework introduced by (Sharma, Sivakumaran and Marshall 2010a, b) that incorporates three consumer traits, namely consumer impulsiveness (CI), optimum stimulation level (OSL), and self-monitoring (SM). Specifically, it shows that CI and OSL have a positive influence, whereas SM has a negative effect on the level of impulse buying in purchase decisions (LIB), and that SM negatively moderates the influence of CI and OSL on LIB. However, this model was only tested in the context of goods, and it ignored the role of perceived risk in impulse buying context. 
We extend this framework using perceived risk as the unifying theme and the driving mechanism for the differences in the level of impulsiveness in purchase decisions.

Services are generally higher on perceived risk compared to goods, with some services being associated with higher perceived risk than others (Murray and Schlacter 1990). For example, services higher in intangibility and credence are associated with greater perceived risk than those higher in experience and search attributes respectively (Mitra et al. 1999). In this paper, we combine these diverse perspectives to extend Sharma et al.'s (2010a, b) framework so that it can be used to investigate both goods and services with varying levels of perceived risk.

Specifically, we first hypothesize $(\mathrm{H} 1-\mathrm{H} 2)$ that consumers experience different levels of perceived risk and impulse buying in services with varying levels of attributes (tangible vs. intangible) and evaluation properties (search, experience, and credence). We test these hypotheses in Study 1. Next, we hypothesize (H3-H7) differences in the influence of three consumer traits (consumer impulsiveness, optimum stimulation level, and self-monitoring) on the levels of perceived risk and impulsiveness in purchase decisions for services with varying levels of attributes (tangible vs. intangible) and evaluation properties (search, experience, and credence). We test these hypotheses in Study 2. Finally, we discusses our findings and the contribution, implications, and limitations of this research.

\section{Impulse buying and services}

Impulse buying is defined as a sudden and immediate purchase with no pre-shopping intentions either to buy the specific product category or to fulfill a specific buying task, and with little or no deliberation or consideration of available alternatives (Beatty and Ferrell 1998). Impulse buying accounts for about $40 \%$ of department store purchases and for up to $80 \%$ of products such as candies and magazines in the U.S. (Abrahams 1997; Smith 1996). However, 
prior research on impulse buying focuses almost exclusively on goods and largely ignores the services context.

Services are generally associated with smaller "consideration sets" compared to goods and hence exploratory behavior such as brand switching is less likely in services compared to goods (Brand and Cronin 1997). Moreover, consumers may associate services with higher perceived risk and variability compared to goods (Murray and Schlacter 1990). All this may suggest a relatively lower likelihood of impulse buying in services than in goods, which possibly explains the lack of interest in this area in past research. However, a few researchers suggest the importance of impulse buying in the services context as well.

For example, a report by Roper Starch Worldwide (Waldrop 1994) shows that 51\% of Americans make the decision to eat outside their home at the last minute, with more young adults (64\%) from low-income households (65\%) likely to decide impulsively to eat outside their home, especially at fast food restaurants (75\%). Similar results are reported for subscribers of financial reports and stock market quotes (Phau and Poon 2000), users of banking services (Agrawal and Schmidt 2003), and users of mobile shopping services (Chiang and Liao 2004). However, due to the descriptive nature of these studies, there is still limited knowledge about what types of services are more likely to experience impulse buying.

To address the paucity of theory-based rigorous empirical research on impulse buying in services, we first use two well-established typologies to explore the differences in the level of impulse buying in services, based on service attributes — intangible vs. tangible (Berry 1980) and service evaluation properties — search, experience, and credence (Parasuraman, Berry and Zeithaml 1985). In fact, services with high tangible attributes may also be high in search and experience properties, whereas services with high credence properties may have more intangible 
attributes. Hence, these two typologies provide a comprehensive way to classify services, and we use them to hypothesize differences in the level of impulse buying in different types of services.

Tangible vs. intangible attributes

Most service offerings are a combination of tangible and intangible attributes (Berry 1980); however, some services (e.g., a retail store, restaurant, or hospital) have highly tangible attributes such as colors, lighting, scent, and music, whereas others (e.g., education, consulting, or financial services) have relatively more intangible attributes such as knowledge, expertise, and trust (Shostack 1977). Intangibility makes it difficult for consumers to evaluate services and increases their perceived risk (Murray and Schlacter 1990); hence, it may have a negative effect on impulse buying, a spontaneous and unreflective response (Dholakia 2000; Rook 1987).

Intangibility is generally associated with greater ambiguity and perceived risk; the level of impulse buying is inversely proportional to the level of perceived risk (Lee and Yi 2008). Perceived risk is also positively associated with search behavior (Beatty and Smith 1987), and hence we argue that by triggering greater search, perceived risk may inhibit impulse buying behavior. Therefore, consumers may be less likely to indulge in impulse buying for services with higher intangible attributes compared to those with higher tangible attributes. Hence,

H1: Consumers experience (a) lower perceived risk and (b) higher likelihood of impulse buying for services with greater tangible (vs. intangible) attributes.

Search, experience and credence properties

Services are also classified using their search, experience, and credence properties, which are based on the amount of pre-purchase knowledge available to consumers (Mitra, Reiss and Capella 1999; Parasuraman, Berry and Zeithaml 1985). Specifically, consumers find it easy to 
use their pre-purchase knowledge to assess the quality of services with higher search properties (e.g., opening a bank account). In contrast, pre-purchase knowledge is not enough for services with higher experience properties and consumers need to experience the service to be able to assess its quality (e.g., hotel stay). Finally, for services with higher credence properties, consumers may find it difficult to evaluate service quality even after consumption (e.g., consulting). We use the following examples to further illustrate the differences among these services:

- Search properties are those attributes that the consumers can easily identify and use to evaluate the service quality before purchase (Mitra, Reiss and Capella 1999). For example, a bank account has attributes such as costs, ease of use, interest rates, and other fees, which are easy to search for and evaluate before opening an account.

- Experience properties are those attributes that are difficult to search for and whose quality is difficult to evaluate before the consumer actually purchases and experiences the service (Mitra, Reiss and Capella 1999). For example, a hotel stay has attributes such as hospitality, comfort, courtesy, and convenience, which are difficult to evaluate before one actually stays in the hotel and experiences these attributes firsthand.

- Credence properties are those attributes that are difficult to search for and to use for evaluating service quality not only before purchasing the service but even after experiencing it (Mitra, Reiss and Capella 1999). For example, consulting services require mutual trust, respect, confidence, and commitment, which are properties difficult to judge even after one has worked with a consultant for many years over several projects. 
Based on the above, consumers seem to have the highest amount of pre-purchase knowledge (pertaining to service quality) available for services with high search properties followed by those with high experience and then credence properties. As a result, consumers may perceive the lowest level of risk for the services with high search properties followed by those with high experience and credence properties respectively. Since the level of perceived risk is inversely proportional to the level of impulse buying (Lee and Yi 2008) and directly proportional to search behavior (Beatty and Smith 1987), services with high search properties may help the consumers in their search process under higher perceived risk and hence experience greater levels of impulse buying compared to those with high experience and credence properties (Mortimer and Pressey 2013). Therefore, we hypothesize:

H2a: Consumers experience (i) lower perceived risk and (ii) higher likelihood of impulse buying for services with greater search (vs. experience) properties.

H2b: Consumers experience (i) lower perceived risk and (ii) higher likelihood of impulse buying for services with greater experience (vs. credence) properties.

\section{Pretest: services classification}

The purpose of this pretest was to classify and shortlist services based on two attributes (intangible vs. tangible) and three evaluation properties (search, experience, and credence) from a list of 50 commonly used services compiled from an exhaustive literature review. A team of five undergraduate students contacted about 500 retail shoppers in a major shopping mall in Singapore and recruited 240 participants (females $=53 \%$, married $=58 \%$ ), with most of them in the 21-60 years age group (84\%) and with monthly household income in the S\$2000-5000 (about US\$1500-3750) range (88\%). The response rate was quite high (about 48\%), and each 
participant received a shopping coupon worth $\$$ \$10 (about US\$8) that could be redeemed at many stores in the shopping mall used in this pretest.

A structured questionnaire was prepared introducing this pretest as a shopper's survey on the first page. The next page listed 10 services randomly selected from the 50 services, and the participants rated each service on two attributes (tangible vs. intangible) and three evaluation properties (search, experience, and credence). Five versions of the questionnaire were prepared to cover all the 50 services (10 in each version). The tangible and intangible attributes were operationalized with an eight-item scale adapted from SERVQUAL (Parasuraman, Zeithaml and Berry 1988) and the evaluation properties with a nine-item scale adapted from Mitra et al. (1999), both using a seven-point Likert scale $(1=$ Strongly disagree to $7=$ Strongly agree $)$. Finally, demographics (age, gender, education, occupation, marital status, monthly household income, ethnicity — Chinese vs. others — and residence status - local, expatriates, tourist) were recorded. Table 1 summarizes the demographic characteristics of the samples in all the studies.

$<$ Insert table 1 about here $>$

Confirmatory Factor Analysis with Maximum Likelihood Method using AMOS 19.0 on the measurement model shows a good fit $\left(\chi^{2}=11.3, d f=5, \chi^{2} / d f=2.26\right.$, RMSEA $=.036$, SRMR $=.049, \mathrm{CFI}=.98)$ with all the fit-indices satisfying the cut-off values $\left(1<\chi^{2} / d f<3\right)$ suggested by Wheaton et al. (1977) and as advised by Hu and Bentler (1999) (RMSEA <.06, SRMR <.08, CFI $>.95$ ). All the parameter estimates (factor loadings) are high $(>.70)$ and load on the expected factors with large t-values (9.87 to 16.53) with no significant cross-loadings (Anderson and Gerbing 1988). High item-to-total correlations (.51 to .67) and average variance extracted (.59 to .66) demonstrate convergent validity; the average variance extracted in each factor exceeds the square of its correlations with all the other constructs, showing discriminant validity 
(Fornell and Larcker, 1981). All the scales are also reliable, with their composite reliabilities ranging from .80 to .85 . Table 2 shows the psychometric properties for all the scales used in the pretest, and Table 3 shows the correlation matrices for all the studies.

$<$ Insert table $2 \& 3$ about here $>$

Next, we calculated the average scores for the two attributes and the three evaluation properties for all the 50 services. We then used one-way ANOVA to classify each service as high on an attribute or evaluation property if it had a significantly higher score on one of the attributes or properties compared to the others. For example, air travel is categorized as high on tangible and low on intangible attributes, whereas college education is classified as low on tangible and high on intangible attributes. Similarly, a bank account is rated as high on search properties and low on the other two properties, a hair salon as high on experience and low on the others, and career advice as high on credence and low on the others.

Using this process, all those services that did not show significant differences between the scores for the two attributes and the three evaluation properties were eliminated. A shortlist was constructed of only those services which clearly had a high score on either tangible or intangible attributes and on search, experience, or credence properties, resulting in 15 services each with high tangible and intangible attributes, along with 10 services each with high search, experience and credence properties. Table 4 shows the 30 shortlisted services and their overall classification along with the average scores on each of these attributes and properties for all the 30 services. Next, we describe our first study conducted to test the first two hypotheses, using a sample and methodology similar to those used in the pretest.

$<$ Insert table 4 about here $>$

\section{Study 1}


Sample and procedure

About 800 retail shoppers were contacted by 10 trained undergraduate students in 10 major shopping malls all over Singapore, and 352 of them were successfully recruited (53\% females, $59 \%$ married). The response rate (44\%) was within the $37-48 \%$ range reported in prior research using a similar approach (Beatty and Ferrell 1998; Rook and Fisher 1995; Sharma, Sivakumaran and Marshall 2010a, b). Most participants were in the 21-60 year age-group (85\%) and with monthly household income in the S\$2000-5000 (about US\$1500-3750) range (90\%). Similar to the pretest, each participant was given a shopping coupon worth S\$10 (about US\$8), which could be redeemed in all the 10 shopping malls included in this study. The data were collected throughout the shopping hours (10am-10pm) during the months of March-April (with no major festivals or promotions) to ensure that the sample represents the average shoppers in these shopping malls.

A structured questionnaire introduced the study as a customer survey about goods and services. On the first page, it listed the 30 services identified in the pretest and asked the participants to rate their perceived risk (PR) and likelihood of impulse buying (LIB) for each of these services. We used a four-item, seven-point semantic differential scale adapted from Campbell and Goodstein (2001) for perceived risk and a five-item scale with a seven-point Likert-scale $(1=$ strongly disagree to $7=$ strongly agree $)$ adapted from Rook and Fisher (1995). Finally, all the demographics were recorded, as summarized in Table 1.

Data analysis

The measurement model shows a good fit $\left(\chi^{2}=62.48, d f=26, \chi^{2} / d f=2.40\right.$, RMSEA $=$ $.042, \mathrm{SRMR}=.064, \mathrm{CFI}=.96)$. All the factor loadings are significant $(>.70)$ with high $\mathrm{t}$-values 
(ranging from $9.33-18.58$ ), average variance extracted $(.62-.66)$ and high composite reliability $(.84-.86)$. Table 5 shows the psychometric properties for each item for both the scales.

$<$ Insert table 5 about here $>$

Next, we used Multivariate Analysis of Variance (MANOVA) to test the first two hypotheses with the average scores for PR and LIB for each service category as the dependent variables and the two service attributes (tangible and intangible) with the three evaluation properties (search, experience, and credence) as independent variables. As shown in Table 6, the average PR scores are significantly lower for services with higher tangible (vs. intangible) attributes $(\mathrm{F}=7.73, p<.001)$ and for services with higher search properties compared to those with higher experience and credence properties, respectively $(\mathrm{F}=9.37, p<.001)$.

$<$ Insert table 6 about here $>$

In contrast, average LIB scores are significantly greater for services with higher tangible (vs. intangible) attributes $(\mathrm{F}=9.77, p<.01)$ and for services with higher search properties compared to those with higher experience and credence properties, respectively $(\mathrm{F}=8.78, p<$ $.001)$. Hence, both $\mathrm{H} 1$ and $\mathrm{H} 2$ are fully supported. We did not find any interaction between the service attributes and evaluation properties for either PR $(\mathrm{F}=1.13, p>.10)$ or $\operatorname{LIB}(\mathrm{F}=1.37, p>$ .10 ); hence the pattern of greater level of impulse buying in services with higher tangible (vs. intangible) attributes seems stable across services with different levels of evaluation properties.

Overall, the first study confirms that consumers do buy services impulsively and that they experience lack of planning, spontaneity, temptation, little deliberation, and loss of control, just as they do for impulse buying of goods. We also show that perceived risk plays an important role in the process of impulse buying, wherein different types of services trigger varying levels of perceived risk and impulse buying. Next, we review prior research on the differences between 
goods and service to extend an existing conceptual framework for impulse buying in goods, to explore the differences in the impulse buying process between goods and services.

\section{An extended model of impulse buying}

Traditionally, services were differentiated from goods in terms of four characteristics: intangibility, inseparability, heterogeneity, and perishability (Zeithaml 1991). However, recent research identifies many more differences between goods and service. For example, goods and services may also differ in terms of perceived risk, quality assurance, variety, production, pricing, and purchase process (Jackson, Neidell and Lunsford 1995). Consumers are more likely to seek information from personal sources and rely on it for pre-purchase evaluation for services than for goods (Zeithaml 1991). In fact, consumers are more than twice as likely to rely on informal sources for purchase of services ( $85 \%)$ compared to goods $(40 \%)$ because of greater need for customization with services (Williams and Windebank 2001). Consumers also engage in more post- than pre-purchase evaluation, often have a smaller evoked set, and are likely to switch brands less frequently for services than for goods (Friedman and Smith 1993).

In light of the above differences, it would be useful to study impulse buying in goods and services using a common conceptual framework. Sharma et al. (2010b) introduced a framework showing that impulse buying (IB) and variety seeking (VS) are influenced by three consumer traits, namely consumer impulsiveness (CI), optimum stimulation level (OSL), and selfmonitoring (SM). According to this framework, both CI and OSL affect impulse buying positively; SM impacts impulse buying negatively and also negatively moderates the influence of $\mathrm{CI}$ and OSL on the level of impulse buying. This framework has been used to explore impulse buying and variety seeking in goods, but it has ignored the services context. In this paper, we extend this framework by incorporating perceived risk as a focal construct and unifying theme to 
hypothesize differences in the influence of the three consumer traits on the level of impulse buying for services with varying levels of service attributes and evaluation properties.

\section{Consumer impulsiveness (CI)}

Consumer impulsiveness is a relatively stable consumer trait associated with impulsive behaviors such as impulse buying, smoking, overeating, drinking, and overspending (Puri 1996; Sharma, Sivakumaran and Marshall 2011). Consumers with high impulsiveness are more impatient, self-indulgent, and careless compared to those with low impulsiveness (Rook and Fisher 1995). Consumers with higher impulsiveness are also likely to experience more impulsive urges and give in to them more frequently and more easily due to their weaker impulse resistance mechanism and depletion of self-regulatory resources (Vohs and Faber 2007). Highly impulsive consumers may also perceive lower risk in impulse buying (Lee and Yi 2008).

Services with higher intangible attributes are generally associated with greater ambiguity and perceived risk because consumers find it difficult to evaluate them (Murray and Schlacter 1990). Therefore, even highly impulsive consumers are likely to perceive relatively more risk and try to control their impulsive urges when faced with the greater uncertainty and risk offered by services with higher intangible attributes. In contrast, services with higher tangible attributes are relatively easier to evaluate, and so such services may be less risky even for low impulsive customers, resulting in no significant difference in the level of perceived risk for both low and high impulsive consumers. Hence, the following hypotheses:

H3a: CI has a negative effect on the level of perceived risk.

$\mathrm{H} 3 \mathrm{~b}$ : The negative effect of $\mathrm{CI}$ on the level of perceived risk is stronger for services with greater tangible (vs. intangible) attributes. 
Similarly, services with greater search properties are easier to evaluate than those with more experience and credence properties. We expect that consumers with high impulsiveness may be even more likely to perceive lower risk and indulge in more impulsive behavior in services with greater search properties compared to those with greater experience and credence properties respectively. Therefore, we hypothesize as follows:

H3c: The negative effect of $\mathrm{CI}$ on the level of perceived risk is stronger for services with higher search (vs. experience) properties.

H3d: The negative effect of CI on the level of perceived risk is stronger for services with higher experience (vs. credence) properties.

Optimum stimulation level (OSL)

Optimum stimulation level is a property that characterizes individuals in terms of their general response to environmental stimuli (Raju 1980). Specifically, all human beings prefer an optimum level of stimulation, so as to try to increase stimulation when the environmental stimulation is below the optimum level and reduce it when it is above the optimum level. Hence, compared to individuals with low OSL, those with higher OSL are chronically lower in their arousal level, and this makes them indulge in sensation-seeking activities to achieve their desired (optimum) stimulation level (Steenkamp and Baumgartner 1992).

Prior research associates OSL with risk taking and exploratory behaviors (Baumgartner and Steenkamp 1996), brand switching (Van Trijp et al. 1996), new product adoption (Mittelstaedt et al. 1976), and even impulse buying behavior (Sharma, Sivakumaran and Marshall 2010b), which are all inherently risky behaviors because of the uncertainty surrounding a new product or brand or an unplanned purchase. However, consumers with high OSL levels do 
not mind taking this risk; rather, they feed on this risk and hence may be more likely to indulge in such behaviors.

As argued earlier, services with higher tangible attributes and search properties are generally easier to evaluate and thus have lower perceived risk than those with higher intangible attributes and experience or credence properties. Therefore, services with higher tangible and search attributes may provide greater opportunities to the consumers with higher OSL to satisfy their needs for higher stimulation levels by indulging in exploratory and risky purchase behaviors. In contrast, services with higher intangible attributes are more difficult to evaluate, so such services may be more risky even for customers with high OSL, thus resulting in no significant difference in the level of perceived risk for customers with low and high OSL. In other words, consumers with higher OSL (a higher tendency to take risks and indulge in exploratory behaviors) may perceive lower risk when buying services with greater tangible (vs. intangible) attributes and those with greater search (vs. experience and credence) properties respectively. Hence, the following hypotheses:

H4a: OSL has a negative effect on the level of perceived risk.

H4b: The negative effect of OSL on the level of perceived risk is stronger for services with greater tangible (vs. intangible) attributes.

H4c: The negative effect of OSL on the level of perceived risk is stronger for services with higher search (vs. experience) properties.

H4d: The negative effect of OSL on the level of perceived risk is stronger for services with higher experience (vs. credence) properties.

Self-monitoring (SM) 
Self-monitoring is defined as the tendency to modify or adapt one's behavior in response to others' presence or behavior (Snyder 1987). High self-monitors are willing to adapt their behavior to enact clearly defined roles appropriate to different situations; low self-monitors are less willing to put on a show to please those around them, preferring instead to be true to their own attitudes and values across different situations (Snyder 1987). These different orientations lead low and high self-monitors to exhibit different behaviors. For example, high self-monitors seek more variety in public (vs. private), in order to depict themselves as interesting and creative people (Ratner and Kahn 2002). High self-monitors also have a greater desire to appear rational when they feel that their decisions may come under scrutiny by others because they consider themselves as more accountable for their decisions under such circumstances (Lerner and Tetlock 1999). High self-monitors may also exercise greater control on their impulsive urges and indulge in less impulse buying, compared to low self-monitors (Luo 2005; Sharma, Sivakumaran and Marshall 2010b).

Impulse buying is commonly perceived as being normatively incorrect and is often associated with post-purchase negative affect, guilt, and unfavorable evaluation of purchase decision (Dittmar and Drury 2000; Hausman 2000; Rook 1987; Trocchia and Janda 2002). High self-monitors are more motivated to control their impulses compared to low self-monitors, due to their desire to appear rational and prudent. In other words, consumers who are highly concerned about their self-image are less likely to give in to their impulses, and therefore they may be able to develop effective impulse resistance strategies over a period of time (Dholakia 2000). We argue that impulse buying in services may be perceived even more negatively in normative terms than in goods, because it involves a greater perceived level of risk and loss of face in the event of undesirable consequences (Rook and Fisher 1995). Hence, a high self-monitor may perceive 
more risk in a service with greater intangible (vs. tangible) attributes and those with higher credence (vs. experience and search) properties, compared to a low self-monitor. Therefore,

H5a: SM has a positive effect on the level of perceived risk.

H5b: The positive effect of SM on the level of perceived risk is stronger for services with greater intangible (vs. tangible) attributes.

H5c: The positive effect of SM on the level of perceived risk is stronger for services with higher experience (vs. search) properties.

H5d: The positive effect of SM on the level of perceived risk is stronger for services with higher credence (vs. experience) properties.

Moderating role of self-monitoring

Consumer traits have a stronger influence on the behavior of low self-monitors, whereas situational factors affect the behavior of high self-monitors to a greater extent (Becherer and Richard 1978; Ratner and Kahn 2002). Hence, it is not surprising that high self-monitors are more likely to regulate their impulse buying behavior than are low self-monitors, due to its negative normative associations. Specifically, consumers with high impulsiveness and optimum stimulation level show significantly lower levels of impulsiveness in their purchase decisions, if they are also high self-monitors (Sharma, Sivakumaran and Marshall 2010b). We argue that this effect may be even more pronounced for services compared to goods because services are generally associated with higher perceived risk and high self-monitors may be more concerned about losing face if they are found to have acted impulsively. Moreover, this effect may be stronger for service with greater intangible (vs. tangible) attributes and those with higher credence (vs. experience and search) properties due to their greater levels of perceived risk. Hence, we hypothesize as follows: 
H6a: SM has a negative moderating effect on the influence of (i) CI and (ii) OSL on perceived risk.

H6b: The negative moderating effect of SM on the influence of (i) CI and (ii) OSL on perceived risk is stronger for services with greater intangible (vs. tangible) attributes.

H6c: The negative moderating effect of SM on the influence of (i) CI and (ii) OSL on perceived risk is stronger for services with greater experience (vs. search) properties.

H6d: The negative moderating effect of SM on the influence of (i) CI and (ii) OSL on perceived risk is stronger for services with greater credence (vs. experience) properties.

Perceived risk

Consumers perceive a certain level of risk when making a purchase, and this may influence their evaluations, choices, and behaviors for new product adoption, store selection, advertising effectiveness, information acquisition, use of word-of-mouth information, and brand loyalty (Lee and Yi 2008). Consumers may also act more impulsively if they perceive low risk in a purchase situation and vice versa (Lee and Yi 2008). Perceived risk may also be an important constraining factor that could attenuate the impact of buying impulse and prevent enactment of impulsive behaviors by triggering of resistance strategies (Dholakia 2000) or normative influences (Rook and Fisher 1995). Hence, we hypothesize as follows:

H7: Perceived risk has a negative effect on the level of impulsiveness in purchase decisions

$<$ Insert figure 1 about here $>$ 
Figure 1 shows the structural model, and Table 7 summarizes all the above hypotheses (H3-H7). Next, we describe our second study, conducted to test these hypotheses.

$<$ Insert table 7 about here $>$

\section{Study 2}

Sample and procedure

This study used a 2 (service attribute - tangible and intangible) X 3 (evaluation property - search, experience and credence) between-subjects lab-experiment with 240 part-time postgraduate students recruited in a major Hong Kong university in return for a HK\$20 (about US\$2.50) lunch coupon. This sample was relatively younger (21-40 years, $83 \%)$, male (55\%), better educated (undergraduate and above, 91\%), and employed (78\%) compared to the pretest and Study 1. However, being mature part-time postgraduate students, all the participants are adult shoppers and hence suitable for a study of impulse buying behavior in services.

All the participants completed a trait scale at the beginning of a new semester as a part of signing up for research studies. We conducted the actual experiment about a month later to minimize the impact of demand effects. For the main study, we identified six services based on their average scores on two attributes (tangible vs. intangible) and three evaluation properties (search, experience, and credence), as shown in Table 8.

$<$ Insert table 8 about here $>$

We chose these services based on a pretest, which a different sample $(n=40)$ of part-time postgraduate students similar to the participants in this study found relevant and easy to identify with. We developed brief descriptions for each service and randomly assigned 40 participants to each service. After reading the description, the participants recorded their levels of perceived risk and impulsiveness in purchase decisions. We then checked our manipulation of the service 
attributes and evaluation properties using the same scale as in our pretest. After completing the study, we gave a HK\$20 lunch coupon to each participant and thanked, debriefed, and dismissed them. None of the participants could guess the real purpose of the study or any of the hypotheses.

\section{Questionnaire and measures}

The trait survey at the beginning of the semester included a six-item reduced scale adapted from Sharma et al. (2011) for CI, a four-item reduced scale adapted from Steenkamp and Baumgartner (1995) for OSL, and a five-item scale adapted from Lennox and Wolfe (1984) for SM; all with seven-point Likert scales $(1=$ strongly disagree and $7=$ strongly agree $)$. During the experiment, we measured perceived risk (PR) with a four-item, seven-point semantic differential scale adapted from Campbell and Goodstein (2001) and the level of impulsiveness in purchase decision (IB) with a five-item scale adapted from Rook and Fisher (1995). Table 9 shows all the scale items and their psychometric properties.

$<$ Insert table 9 about here $>$

Data analysis

Confirmatory Factor Analysis shows a good fit for the measurement model $\left(\chi^{2}=533.34\right.$, $\left.d f=220, \chi^{2} / d f=2.42, \mathrm{RMSEA}=.042, \mathrm{SRMR}=.064, \mathrm{CFI}=.96\right)$ and good psychometric properties for all the scales, with high parameter estimates $(>.70)$ on the expected factors with large t-values (12.42 to 16.36) and no significant cross-loadings (Anderson and Gerbing 1988). High item-to-total correlations (.50 to .62) and average variance extracted (.59 to .66) show convergent validity; the average variance extracted in each factor exceeds the square of its correlations with all the other constructs, showing discriminant validity (Fornell and Larcker 1981). All the scales show high composite reliabilities, ranging from .82 to .88 . 
We first tested all the hypothesized main effects (H3a, H4a, H5a, and H7) using the basic structural model with the pooled data from all the services. The model provides a good fit $\left(\chi^{2}=\right.$ 389.46, $\left.d f=167, p<.001, \chi^{2} / d f=2.33, \mathrm{CFI}=.96, \mathrm{RMSEA}=.042, \mathrm{SRMR}=.063\right)$, and all the hypothesized effects are in the expected direction. Specifically, both CI $(\beta=-.27, p<.001)$ and $\operatorname{OSL}(\beta=-.23, p<.001)$ have a significant negative effect on $\mathrm{PR}$, and $\operatorname{SM}(\beta=.32, p<.001)$ has a positive effect on PR. Moreover, PR has a negative effect on LIB $(\beta=-.36, p<.001)$. Hence, all the main effects (H3a, H4a, H5a, and H7) are supported, as hypothesized.

Next, we tested the moderating impact of SM on the influence of CI and OSL on PR, using an "unconstrained mean-centered" approach (Marsh et al. 2007) to overcome the limitations of the "constrained" approach (Moulder and Algina 2002). Moreover, the three independent variables are not strongly correlated in this case so multi-collinearity is not a problem, and hence it does not need "residual-centering" approach (Little, Bovaird and Widaman 2006). We mean-centered all the items for the three independent variables (CI, OSL, and SM) and created two interaction terms, SM X CI and SM X OSL, by multiplying the items for the respective constructs with each other.

We tested the structural model with CI, OSL, SM, SM X CI, and SM X OSL as the independent variables and PR as the dependent variable and found a good fit to the data $\left(\chi^{2}=\right.$ 478.28, $\left.d f=206, p<.001, \chi^{2} / d f=2.32, \mathrm{CFI}=.97, \mathrm{RMSEA}=.038, \mathrm{SRMR}=.054\right)$. All the path coefficients are significant and in the expected directions. As hypothesized, both $\mathrm{CI}(\beta=-.24, p$ $<.001)$ and OSL $(\beta=-.21, p<.001)$ have a significant negative effect on PR, whereas SM $(\beta=$ $.35, p<.001)$ has a positive effect on PR. Next, we tested the differences in the strength of each link in the model between different types of services by constraining each link separately to be equal across the five sub-groups and by testing the significance of the differences in the $\chi^{2}$ values 
with that for the general unconstrained model with the five sub-groups. We found significant differences in the regression weights (path coefficients) for most of the linkages in the model.

$<$ Insert table 10 about here $>$

As shown in Table 10, all the hypotheses are supported except H5b. We also tested for the mediating role of perceived risk (PR) between the three independent variables (CI, OSL, and SM) and the dependent variable (IB) using the method proposed by (Iacobucci, Saldanha and Deng 2007). For this, we first tested a model with a direct path from the three independent variables and their interaction terms to the dependent variable, and an indirect path via perceived risk. This model has a good fit, with the three independent variables, $\mathrm{CI}(\beta=.17, p<.01)$, OSL $(\beta=.13, p<.01)$, and SM $(\beta=-.10, p<.05)$, showing small but significant direct effects on IB. Moreover, the interaction terms (SM X CI and SM X OSL) have no significant direct effect on IB. Thus we found evidence only for partial mediation.

Next, we explicitly tested the relative sizes of the indirect (mediated) vs. direct paths by calculating the $\mathrm{z}$-value using the formula: $\mathrm{z}=(\mathrm{a} * \mathrm{~b}) /\left(\mathrm{b}^{2} \mathrm{~s}_{\mathrm{a}}{ }^{2}+\mathrm{a}^{2} \mathrm{~s}_{\mathrm{b}}{ }^{2}\right)^{1 / 2}$, where $\mathrm{a}$ is the unstandardized regression coefficient for the association between an independent variable (CI, OSL, or $\mathrm{SM}$ ) and the mediator (PR), and $\mathrm{s}_{\mathrm{a}}$ is the standard error of a. Similarly, $\mathrm{b}$ is the unstandardized regression coefficient for the association between the mediator (PR) and the dependent variable (IB), and $\mathrm{s}_{\mathrm{b}}$ is the standard error of $\mathrm{b}$ when the independent variable is also included as a predictor in the model. Using the above formula, we found that the direct as well as indirect effects of the three independent variables and their interaction terms on the dependent variable via the mediator are significantly different from zero. Hence, these findings support a partial-mediation model (Iacobucci, Saldanha and Deng 2007). 
Overall, this model explains about two-thirds variance $\left(\mathrm{R}^{2}=.63\right)$ in the dependent variable (level of impulsiveness in purchase decision). Thus, Study 2 helps test the extended conceptual framework and provides many useful insights about the differences in the impact of three relevant consumer traits (CI, OSL, and SM) on the process and outcome of impulse buying in services with varying levels of attributes and evaluation properties.

\section{General discussion}

This research makes several important conceptual contributions. First, it is one of the few attempts to empirically demonstrate the existence of impulse buying behavior in the services context. Second, it demonstrates which types of services are more likely to experience impulse buying based on their attributes and evaluation properties, using well-established typologies. Third, it extends an existing conceptual framework, used in the past mostly for impulse buying in goods, to explain its incidence in both goods and services by introducing perceived risk as the underlying theme and a focal construct in the model. In this process, this paper highlights several important differences in the influence of three relevant consumer traits on impulse buying behavior in different types of services, which add to our knowledge of impulse buying in general and may pave the way for a better understanding of impulse behaviors in a broader context.

Prior research on impulse buying has focused mostly on the goods and ignored services, despite the important contribution of everyday services in a consumer's life. One of the possible reasons for this may be the higher level of perceived risk associated generally with services than with goods. However, as shown by many researchers, there are many psychological and social factors that influence how different consumers behave in the same situation or how the same consumer may behave differently under different situations. In view of the above, this paper 
explores the incidence of impulse buying in the services context using an integrative conceptual framework for impulse buying in both goods and services.

Prior research on impulse buying has identified several antecedents of impulse buying behavior. For example, Beatty and Ferrell (1998) find that time and money availability and impulse buying tendency are key drivers of impulsive urges. In contrast, Sharma et al. (2010a, b) identify three consumer traits (CI, OSL, and SM) as primary drivers of impulse buying, and (Mohan, Sivakumaran and Sharma 2013) show that various elements of store environment may also contribute to impulse buying. However, all these studies were conducted in the context of goods, and in this paper we extend Sharma et al.'s work by including perceived risk as a focal construct in the impulse buying process and by studying the impact of CI, OSL, and SM in services context.

First, a study with retail shoppers in Singapore shows that consumers do buy services impulsively, but the level of perceived risk and likelihood of impulse buying (LIB) varies across different types of services. Specifically, consumers seem to experience lower levels of perceived risk and greater impulse buying in services with higher tangible (vs. intangible) attributes. Similarly, services with higher search properties seem to relate with lower perceived risk and greater level of impulse buying, compared to services with higher experience and credence properties. Both these findings not only extend the prior research on impulse buying, but also add to our growing knowledge about the differences among various types of services (e.g., Anderson, Fornell and Rust 1997; Jackson, Neidell and Lunsford 1995; Laroche, Bergeron and Goutaland 2001; Miller and Foust 2003) first identified several decades ago (Lovelock 1983; Shostack 1977). 
Next, this paper extends an existing conceptual framework introduced by Sharma et al. (2010b) to explore impulse buying in goods, by incorporating perceived risk as a focal construct in order to investigate the differences in the influence of three relevant consumer traitsconsumer impulsiveness, optimum stimulation level, and self-monitoring — on services with varying attributes and evaluation properties. The results show that, similar to the goods context, consumers with high scores on CI and OSL are also likely to indulge in greater level of impulse buying in services compared to those with low scores on these two traits. More importantly, we also show that the influence of both CI and OSL is partially mediated by perceived risk and that both these consumer traits have a stronger influence on services with greater tangible (vs. intangible) attributes and search (vs. experience and credence) properties respectively. These are important findings as they provide first empirical evidence of the focal role played by perceived risk in the impulse buying process for different types of services. Future research on impulse buying behavior may benefit by including perceived risk as a possible mediator.

Next, we show that self-monitoring has a positive impact on perceived risk that in turn reduces the level of impulsiveness in purchase decision. Self-monitoring also has a stronger influence on perceived risk and impulsiveness in purchase decisions for services with greater intangible (vs. tangible) attributes and credence (vs. experience and search) properties. However, the difference in the influence of self-monitoring on perceived risk between services with higher search and experience properties (H5b) is in the expected direction but not statistically significant, possibly due to the relatively small sample size for each service $(n=40)$.

We show a similar pattern for the negative moderating effect of self-monitoring on the influence of CI and OSL on perceived risk and level of impulsiveness in purchase decisions for services with higher tangible (vs. intangible) attributes and search (vs. experience and credence) 
properties respectively. These results suggest that the negative normative associations and risk perceptions of impulse buying may be stronger in services with greater intangible (vs. tangible) attributes and higher credence (vs. experience and search) properties. By incorporating these important insights about the differences in the antecedents of impulse buying between different types of services, we extend the conceptual framework developed by Sharma et al. (2010b) and in this process address an important gap in the extant research on impulse buying behavior.

Besides its conceptual contributions, this research also has some useful managerial implications. For example, it shows that impulsive consumers tend to buy some services (e.g., those with higher tangible attributes and search properties) more impulsively than others (e.g., those with higher intangible attributes and experience or credence properties). Prior research suggests that marketers should make their service features more tangible in order to make the intangible nature of their services more "palpable and easy to grasp mentally" in order to differentiate from their competitors (Berry 1980).

Our findings extend prior research by showing that improving the tangible attributes or using suitable tangible cues can help services marketers trigger more impulse buying for their services. For instance, services low on tangibility such as beauty care may use beautiful models in their advertising with good looking staff and attractive displays in their outlets. Further, after treatment, they may give tangible cues to consumers in the form of high-quality cosmetic goods. This may not only lower the perceived risk for existing consumers but also attract others who may see these tangible cues in friends' homes and in other settings. Marketers of other services with higher intangible attributes may also undertake similar efforts. For example, healthcare and education services may use tangible cues such as brochures, interviews with real patients or students, and visuals of their modern equipment and facilities to attract new customers. 
We also show that high OSL consumers buy services more impulsively to satisfy their need for stimulation; hence services marketers may enhance the sensations associated with their services to trigger impulse buying for their services. For example, service providers such as fitness clubs and adventure sports companies could arrange free trials for their potential customers in order to attract those with high need for stimulation. Moreover, self-monitoring has a stronger negative effect on impulse buying in services, so services marketers need to train their front-line employees to identify high self-monitors and try to allay their concerns and make them more comfortable in order to increase their chances of buying the services.

We also show that services high in search properties (e.g., fast food restaurants) are likely to experience more impulse buying than those high in experience and credence properties. Hence, firms selling services high in experience properties (e.g., foot massage parlors) may have to work on reducing the perceived risk by giving information about how nice a foot massage would be, how soothing it would be, and how others who have experienced it have felt its positive effects. Testimonial advertisements from credible sources such as satisfied customers or experts would possibly go some distance toward making this kind of service appear to be higher on search qualities, and this in turn may enhance impulse buying. Firms with higher levels of credence properties (e.g., beauty care or weight loss clinics) may follow a similar strategy.

Overall, we demonstrate that several consumer traits influence impulse buying in services in a manner similar to that of goods. While it was traditionally believed to be hard to target specific personality types, recent technologies have enabled this process. For instance, there are companies such as Mindset Media (www.mindsetmedia.com) that help marketers target specific personality types and marketers may use their services to target consumers with high CI, OSL, and low SM. Moreover, service firms may use client sign-up forms to gather data from their new 
or repeat customers about their personality variables (e.g., CI). This can help customize the offers to be sent to these customers and result in more effective promotional offers.

\section{Limitations and future research}

Despite its many contributions, this research also has some limitations. First, both our studies were conducted in developed consumer markets in Asia (Singapore and Hong Kong) with high disposable incomes and living standards. Hence, our results may not be applicable to less developed Asian markets. Moreover, prior research shows many cross-cultural differences in impulse buying behavior (Kacen and Lee 2002; Lee and Kacen 2008) as well as the consumer impulsiveness trait (Sharma, Sivakumaran and Marshall 2011). Hence, we need more research with consumers from diverse cultural and socio-economic backgrounds to test the generalizability of our results.

Future research may also look beyond the three consumer traits used (i.e., CI, OSL, and SM) and examine the role of other individual and situational factors to develop a more comprehensive conceptual framework for impulse buying in both goods and services. In this research, we adapted existing scales to operationalize the service attributes and evaluation properties, and more research is needed to test their validity and generalizability. Finally, we used a mall-intercept survey in our first study and a lab-experiment in our second study. Future research may use other methods (say, field-experiments) to test the generalizability of our findings, using a wider variety of goods and services with varying levels of service attributes, evaluation properties, perceived risk, involvement level, and other unique characteristics.

\section{References}

Abrahams, Ben. 1997. "It's All in the Mind." In Marketing, 31-33. 
Adelaar, Thomas, Susan Chang, Karen M. Lancendorfer, Byoungkwan Lee, and Mariko Morimoto. 2003. "Effects of media formats on emotions and impulse buying intent." Journal of Information Technology 18 (4): 247-266.

Agrawal, M. L., and Marcus Schmidt. 2003. "Listening Quality of the Point of Service Personnel (PSPS) as Impulse Trigger in Service Purchase: A Research Framework." Journal of Services Research 3 (1): 29-43.

Anderson, Eugene W., Claes Fornell, and Roland T. Rust. 1997. "Customer Satisfaction, Productivity and Profitability: Differences between Goods and Services." Marketing Science 16 (2): 129-145.

Baumgartner, Hans, and Jan-Benedict E. M. Steenkamp. 1996. "Exploratory Consumer Buying Behavior: Conceptualization and Measurement." International Journal of Research in Marketing 13 (April): 121-137.

Bayley, Geoff, and Clive Nancarrow. 1998. "Impulse purchasing: a qualitative exploration of the phenomenon." Qualitative Market Research: An International Journal 1: 99-114.

Beatty, Sharon E., and Elizabeth M. Ferrell. 1998. "Impulse Buying: Modeling its Precursors." Journal of Retailing 74 (2): 169-191.

Beatty, Sharon E., and Scott M. Smith. 1987. "External Search Effort: An Investigation Across Several Product Categories." Journal of Consumer Research 14 (1): 83-95.

Becherer, Richard C., and Lawrence M. Richard. 1978. "Self-monitoring as a moderating variable in consumer behavior." Journal of Consumer Research 5: 159-162.

Berry, Leonard L. 1980. "Services Marketing is Different." Business (May-June): 24-29.

Brand, Richard R., and Joseph J. Cronin. 1997. "Consumer-specific determinants of the size of retail choice sets: an empirical comparison of physical goods and service providers." The Journal of Services Marketing 11 (1): 19-38.

Campbell, Margaret C., and Ronald C. Goodstein. 2001. "The Moderating Effect of Perceived Risk on Consumers' Evaluations of Product Incongruity: Preference for the Norm." Journal of Consumer Research 28 (3): 439-449.

Chiang, Heien-Kun, and Yi-Wen Liao. 2004. "An Agent-based Framework for Impulse-induced Mobile Shopping." In Fourth International Conference on Computer and Information Technology.

Crawford, Gerry, and T. C. Melewar. 2003. "The importance of impulse purchasing behaviour in the international airport environment." Journal of Consumer Behaviour 3 (1): 85.

Dholakia, Utpal M. 2000. "Temptation and Resistance: An Integrated Model of Consumption Impulse Formation and Enactment." Psychology \& Marketing 17 (11): 955-982. 
Dittmar, Helga, and John Drury. 2000. "Self-image - is it in the bag? A qualitative comparison between "ordinary" and "excessive" consumers." Journal of Economic Psychology 21: 109-142.

Friedman, Margaret L., and Lois J. Smith. 1993. "Consumer evaluation processes in a services setting." Journal of Services Marketing 7 (2): 47-61.

Hausman, Angela. 2000. "A multi-method investigation of consumer motivations in impulse buying behavior." Journal of Consumer Marketing 17 (5): 403-419.

Iacobucci, Dawn, Neela Saldanha, and Xiaoyan Deng. 2007. "A Meditation on Mediation: Evidence That Structural Equations Models Perform Better Than Regressions." Journal of Consumer Psychology 17 (2): 140-154.

Jackson, R. W., L. A. Neidell, and D. A. Lunsford. 1995. "An Empirical Investigation of the Differences in Goods and Services as Perceived by Organizational Buyers." Industrial Marketing Management 24 (2): 99-108.

Jeffrey, Scott A., and Rebecca Hodge. 2007. "Factors influencing impulse buying during an online purchase." Electronic Commerce Research 7 (3-4): 367-379.

Jones, Michael A., Kristy E. Reynolds, Seungoog Weun, and Sharon E. Beatty. 2003. "The product-specific nature of impulse buying tendency." Journal of Business Research 56: 505-511.

Kacen, Jacqueline J., and Julie Anne Lee. 2002. "The influence of culture on consumer impulsive buying behavior." Journal of Consumer Psychology 12 (2): 163-176.

Kukar-Kinney, Monika, Nancy M. Ridgway, and Kent B. Monroe. 2009. "The Relationship Between Consumers' Tendencies to Buy Compulsively and Their Motivations to Shop and Buy on the Internet." Journal of Retailing 85 (3): 298-307.

Kwak, Hyokjin, George M. Zinkhan, Denise E. DeLorme, and Trina Larsen. 2006. "Revisiting Normative Influences on Impulsive Buying Behavior and an Extension to Compulsive Buying Behavior: A Case from South Korea." Journal of International Consumer Marketing 18 (3): 5780 .

Kwon, Hyungil H., and Ketra L. Armstrong. 2002. "Factors influencing impulse buying of sport team licensed merchandise." Sport Marketing Quarterly 11 (3): 151-163.

Laroche, Michel, Jasmin Bergeron, and Christine Goutaland. 2001. "A Three-Dimensional Scale of Intangibility." Journal of Service Research 4 (1): 26-38.

Lee, Grace Yuna, and Youjae Yi. 2008. "The Effect of Shopping Emotions and Perceived Risk on Impulsive Buying: The Moderating Role of Buying Impulsiveness Trait." Seoul Journal of Business 14 (2): 67-92.

Lee, Julie Anne, and Jacqueline J. Kacen. 2008. "Cultural influences on consumer satisfaction with impulse and planned purchase decisions." Journal of Business Research 61 (3): 265-272. 
Lennox, Richard D., and Raymond N. Wolfe. 1984. "Revision of the Self-Monitoring Scale." Journal of Personality and Social Psychology 46: 1349-1364.

Lerner, Jennifer S., and Philip E. Tetlock. 1999. "Accounting for the effects of accountability." Psychological Bulletin 125: 255-275.

Lin, C. H., and H. M. Lin. 2005. "An exploration of Taiwanese adolescents' impulsive buying tendency." Adolescence 40 (157): 215-223.

Little, Todd D., James A. Bovaird, and Keith F. Widaman. 2006. "On the Merits of Orthogonalizing Powered and Product Terms: Implications for Modeling Interactions among Latent Variables." Structural Equation Modeling 13 (4): 497-519.

Lovelock, Christopher H. 1983. "Classifying services to gain strategic marketing insights." Journal of Marketing 47 (Summer): 9-20.

Lovelock, Christopher, Jochen Wirtz, and Jayanta Chatterjee. 2012. Services Marketing - People, Technology, Strategy. Delhi: Pearson Education (Singapore) Pte. Ltd.

Luo, Xueming. 2005. "How does shopping with others influence impulsive purchasing?" Journal of Consumer Psychology 15 (4): 288-294.

Madhavaram, Sreedhar Rao, and Debra A. Laverie. 2004. "Exploring impulse purchasing on the Internet." Advances in Consumer Research 31: 59-66.

Marsh, Herbert W., Zhonglin Wen, Kit-Tai Hau, Todd D. Little, James A. Bovaird, and Keith F. Widaman. 2007. "Unconstrained Structural Equation Models of Latent Interactions: Contrasting Residual- and Mean-Centered Approaches." Structural Equation Modeling 14 (4): 570-580.

Miller, Darryl W., and Jacque E. Foust. 2003. "Classifying Services by Tangibility/Intangibility of Attributes and Benefits." Services Marketing Quarterly 24 (4): 35-56.

Mitra, Kaushik, Michelle C. Reiss, and Louis M. Capella. 1999. "An examination of perceived risk, information search and behavioral intentions in search, experience and credence services." The Journal of Services Marketing 13 (3): 208-228.

Mohan, Geetha, Bharadhwaj Sivakumaran, and Piyush Sharma. 2013. "Impact of Store Environment on Impulse Buying Behavior." European Journal of Marketing 47 (10): In Press.

Mortimer, Kathleen, and Andrew Pressey. 2013. "Consumer information search and credence services: implications for service providers." Journal of Services Marketing 27 (1): 49-58.

Moulder, Bradley C., and James Algina. 2002. "Comparison of Methods for Estimating and Testing Latent Variable Interactions." Structural Equation Modeling 9 (1): 1-19.

Murray, Keith B., and John L. Schlacter. 1990. "The impact of services versus goods on consumers' assessment of perceived risk and variability." Journal of the Academy of Marketing Science 18 (1): 51-65. 
Nguyen, Thi Tuyet Mai, Kwon Jung, Garold Lantz, and Sandra Loeb. 2003. "An exploratory investigation into impulse buying behavior in a transitional economy: A study of urban consumers in Vietnam." Journal of International Marketing 11 (2): 13-35.

Omar, Ogenyi, and Anthony Kent. 2001. "International Airport Influences on Impulsive Shopping: Trait and Normative Approach." International Journal of Retail and Distribution Management 29 (5): 226-235.

Parasuraman, A., Leonard L. Berry, and Valerie A. Zeithaml. 1985. "A Conceptual Model of Service Quality and its Implications for Future Research." Journal of Marketing 49 (Fall): 41-50.

Parasuraman, A., Valerie A. Zeithaml, and Leonard L. Berry. 1988. "SERVQUAL: A multipleitem scale for measuring consumer perceptions of service quality." Journal of Retailing 64 (1): 12-37.

Park, Jihye, and Sharron J. Lennon. 2006. "Psychological and environmental antecedents of impulse buying tendency in the multichannel shopping." Journal of Consumer Marketing 23 (2): 56-66.

Peck, Joann, and Terry L Childers. 2006. "If I touch it I have to have it: Individual and environmental influences on impulse purchasing." Journal of Business Research 59 (6): 765-769.

Phau, Ian, and Sui Meng Poon. 2000. "Factors influencing the types of products and services purchased over the Internet." Internet Research: Electronic Networking Applications and Policy 10 (2): 102-113.

Puri, Radhika. 1996. "Measuring and Modifying Consumer Impulsiveness: A Cost-benefit Accessibility Framework." Journal of Consumer Psychology 5 (2): 87-113.

Raju, Puthankurissi S. 1980. "Optimal stimulation level: Its relationships to personality, demographics and exploratory behavior." Journal of Consumer Research 7 (December): 272282.

Ratner, Rebecca K., and Barbara E. Kahn. 2002. "The impact of private versus public consumption on variety-seeking behavior." Journal of Consumer Research 29: 246-257.

Rook, Dennis W. 1987. "The buying impulse." Journal of Consumer Research 14 (2): 189-199.

Rook, Dennis W., and Robert J. Fisher. 1995. "Normative influences on impulsive buying behavior." Journal of Consumer Research 22 (3): 305-313.

Sharma, Piyush, Bharadhwaj Sivakumaran, and Roger Marshall. 2010a. "Exploring Impulse Buying and Variety Seeking by Retail Shoppers: Towards a Common Conceptual Framework." Journal of Marketing Management 26 (5-6): 473-494.

Sharma, Piyush, Bharadhwaj Sivakumaran, and Roger Marshall. 2010b. "Exploring Impulse Buying and Variety Seeking: A Trait-Correlates Perspective." Journal of Business Research 63 (3): 276-283. 
Sharma, Piyush, Bharadhwaj Sivakumaran, and Roger Marshall. 2011. "Deliberate SelfIndulgence vs. Involuntary Loss of Self-Control: Towards a Robust Cross-Cultural Consumer Impulsiveness Scale." Journal of International Consumer Marketing 23 (3-4): 229-245.

Shostack, G. Lynn. 1977. "Breaking free from product marketing." Journal of Marketing (April): 73-80.

Smith, Don. 1996. "The Joy of Candy." In National Petroleum News Supplement, S2.

Snyder, Mark. 1987. Public appearances/Private realities: The psychology of self-monitoring. New York: Freeman.

Steenkamp, Jan-Benedict E. M., and Hans Baumgartner. 1992. "The Role of Optimum Stimulation Level in Exploratory Consumer Behavior." Journal of Consumer Research 19 (December): 434-448.

Steenkamp, Jan-Benedict E. M., and Hans Baumgartner. 1995. "Development and cross-cultural validation of a short form of CSI as a measure of optimum stimulation level." International Journal of Research in Marketing 12: 97-104.

Trocchia, Philip J., and Swinder Janda. 2002. "An investigation of product purchase and subsequent non-consumption." Journal of Consumer Marketing 19: 188-204.

Vohs, Kathleen D., and Ronald J. Faber. 2007. "Spent Resources: Self-Regulatory Resource Availability Affects Impulse Buying." Journal of Consumer Research 33 (4): 537-547.

Waldrop, Judith. 1994. "Most restaurant meals are bought on impulse." In American Demographics, 16-17.

Williams, Colin C., and Jan Windebank. 2001. "Acquiring goods and services in lower income populations: an evaluation of consumer behavior and preferences." International Journal of Retail \& Distribution Management 29 (1): 16-27.

Zeithaml, Valerie A. 1991. "How Consumer Evaluation Processes Differ Between Goods and Services." In Services Marketing. Ed. C. H. Lovelock. Upper Saddle River, NJ: Prentice Hall.

Zhou, Lianxi, and Amy Wong. 2003. "Consumer Impulse Buying and In-Store Stimuli in Chinese Supermarkets." Journal of International Consumer Marketing 16 (2): 37-53. 
Figure 1: Overall Structural Model (Study 2)

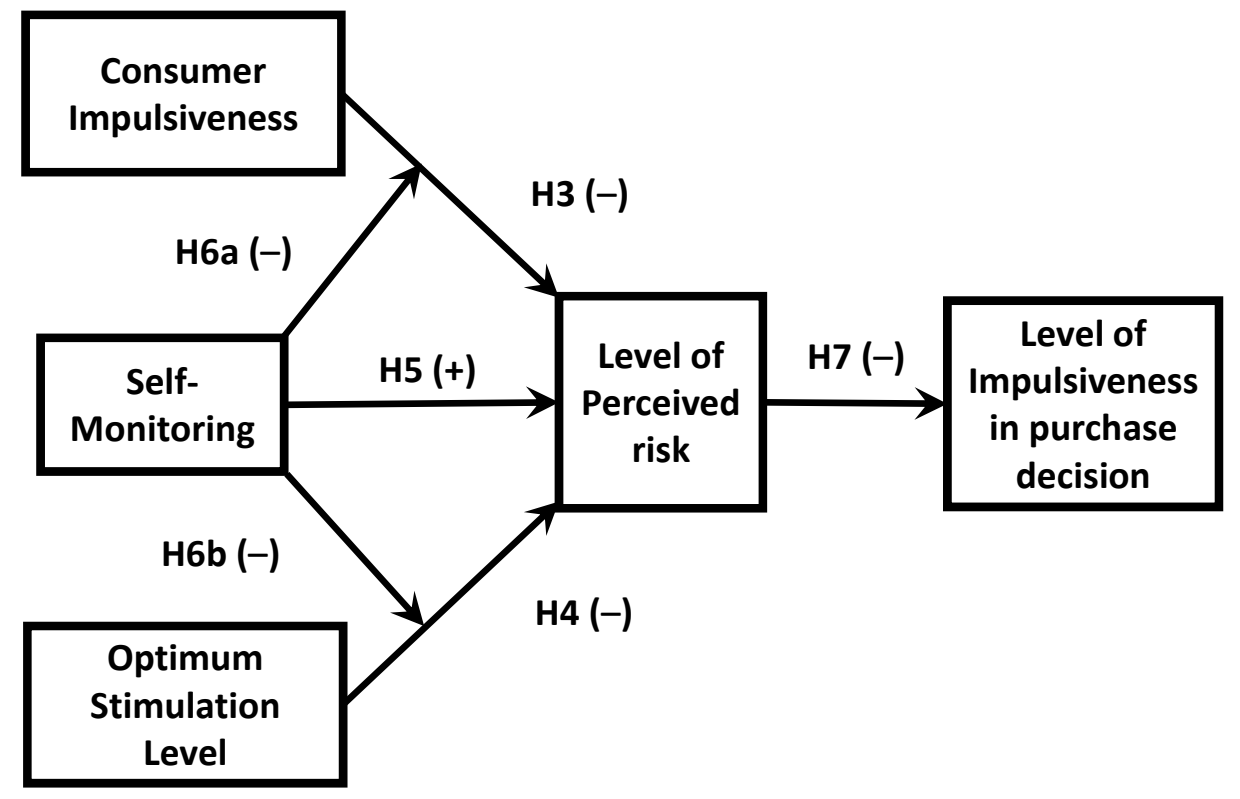


Table 1 - Sample Composition (Demographics)

\begin{tabular}{|c|c|c|c|c|c|c|}
\hline \multirow[t]{2}{*}{$\begin{array}{l}\text { Demographic } \\
\text { Variables }\end{array}$} & \multicolumn{2}{|c|}{$\begin{array}{l}\text { Pretest }(N=240) \\
\text { Singapore }\end{array}$} & \multicolumn{2}{|c|}{$\begin{array}{c}\text { Study } 1(\mathbf{N}=352) \\
\text { Singapore }\end{array}$} & \multicolumn{2}{|c|}{$\begin{array}{c}\text { Study } 2(\mathrm{~N}=240) \\
\text { Hong Kong }\end{array}$} \\
\hline & Nos. & $\%$ & Nos. & $\%$ & Nos. & $\%$ \\
\hline \multicolumn{7}{|l|}{ Age } \\
\hline$<21$ & 24 & $10 \%$ & 35 & $10 \%$ & - & - \\
\hline $21-30$ & 86 & $36 \%$ & 123 & $35 \%$ & 128 & $53 \%$ \\
\hline $31-40$ & 44 & $18 \%$ & 74 & $21 \%$ & 72 & $30 \%$ \\
\hline $41-50$ & 43 & $18 \%$ & 58 & $16 \%$ & 35 & $15 \%$ \\
\hline $51-60$ & 29 & $12 \%$ & 44 & $13 \%$ & 5 & $2 \%$ \\
\hline$>60$ & 14 & $6 \%$ & 18 & $5 \%$ & - & - \\
\hline \multicolumn{7}{|l|}{ Gender } \\
\hline Male & 114 & $48 \%$ & 164 & $47 \%$ & 132 & $55 \%$ \\
\hline Female & 126 & $52 \%$ & 188 & $53 \%$ & 108 & $45 \%$ \\
\hline \multicolumn{7}{|l|}{ Marital Status } \\
\hline Single & 101 & $42 \%$ & 144 & $41 \%$ & 104 & $43 \%$ \\
\hline Married & 139 & $58 \%$ & 208 & $59 \%$ & 136 & $57 \%$ \\
\hline \multicolumn{7}{|l|}{ Education } \\
\hline High School & 92 & $38 \%$ & 139 & $39 \%$ & 15 & $6 \%$ \\
\hline Undergraduate & 123 & $51 \%$ & 173 & $49 \%$ & 204 & $85 \%$ \\
\hline Post-grad \& above & 25 & $11 \%$ & 40 & $12 \%$ & 21 & $9 \%$ \\
\hline \multicolumn{7}{|l|}{ Occupation } \\
\hline Full-time Student & 36 & $15 \%$ & 51 & $14 \%$ & - & - \\
\hline Housewife & 55 & $23 \%$ & 89 & $25 \%$ & - & - \\
\hline Employed & 108 & $45 \%$ & 154 & $44 \%$ & 186 & $78 \%$ \\
\hline Businessman & 22 & $9 \%$ & 36 & $11 \%$ & 54 & $23 \%$ \\
\hline Others & 19 & $8 \%$ & 22 & $6 \%$ & - & - \\
\hline \multicolumn{7}{|c|}{ Monthly Household Income (US\$) } \\
\hline$<1500$ & 17 & $7 \%$ & 28 & $8 \%$ & - & - \\
\hline $1500-2249$ & 69 & $29 \%$ & 132 & $38 \%$ & 68 & $28 \%$ \\
\hline 2250-2999 & 93 & $39 \%$ & 110 & $31 \%$ & 121 & $50 \%$ \\
\hline $3000-3749$ & 49 & $20 \%$ & 75 & $21 \%$ & 33 & $14 \%$ \\
\hline$\geq 3750$ & 12 & $5 \%$ & 7 & $2 \%$ & 18 & $8 \%$ \\
\hline \multicolumn{7}{|l|}{ Ethnicity } \\
\hline Chinese & 186 & $78 \%$ & 278 & $79 \%$ & 211 & $88 \%$ \\
\hline Others & 54 & $23 \%$ & 74 & $21 \%$ & 29 & $12 \%$ \\
\hline \multicolumn{7}{|l|}{ Residence Status } \\
\hline Local & 208 & $87 \%$ & 311 & $88 \%$ & 202 & $84 \%$ \\
\hline Expatriate & 24 & $10 \%$ & 28 & $8 \%$ & 38 & $16 \%$ \\
\hline Tourist & 8 & $3 \%$ & 13 & $4 \%$ & - & - \\
\hline
\end{tabular}


Table 2: Confirmatory Factor Analysis (Pretest)

\section{Service Attributes}

\section{Tangibles (TAN)}

1. It is important to have modern equipment to provide this service $\quad .78 \quad .60$

2. This service should be provided with visually appealing facilities $\quad \begin{array}{lll}.75 & .56\end{array}$

3. The employees providing this service should look smart $\quad .80 \quad .62$

$\begin{array}{lllll}\text { 4. This service should be provided in a comfortable environment } & .81 & .63\end{array}$

\section{Intangibles (INT)}

$\begin{array}{llll}\text { 5. It is important to provide this service right the first time } & .82 & .64\end{array}$

$\begin{array}{llll}\text { 6. The employees providing this service should be knowledgeable } & .84 & .67\end{array}$

$\begin{array}{llll}\text { 7. Prompt service and complaint handling is important for this service } & .78 & .59\end{array}$

8. The employees providing this service should be helpful and caring $\quad \begin{array}{lll}.80 & .61\end{array}$

\section{Service Evaluation Properties}

\section{Search (SEA)}

9. I can get all the information about this service before buying it $\quad \begin{array}{lll}.80 & .62\end{array}$

10. I can evaluate the quality of this service before buying it $\quad \begin{array}{lll}.79 & .60\end{array}$

11. I can evaluate the quality of this service before using it $\quad .76 \quad .57$

\section{Experience (EXP)}

$\begin{array}{llll}\text { 12. I can get all the information about this service only after buying it } & & .72 & .51\end{array}$

$\begin{array}{lll}\text { 13. I can evaluate the quality of this service only after buying it } & .78 & .58\end{array}$

14. I can evaluate the quality of this service only after using it $\quad .80 \quad .61$

\section{Credence (CRE)}

15. I cannot get all the information about this service even after buying it $\quad \begin{array}{lll}.75 & .52\end{array}$

16. I cannot evaluate the quality of this service even after buying it $\quad \begin{array}{lll}.75 & .54\end{array}$

$\begin{array}{lll}\text { 17. I cannot evaluate the quality of this service even after using it } & .78 & .53\end{array}$

$\lambda$ : Factor loadings, $\alpha$ : Item-to-Total Correlations; $\mathrm{M}$ : Mean, $\mathrm{SD}=$ Standard Deviation 
Table 3 - Correlations Matrices

\section{PRETEST}

\begin{tabular}{lccccc}
\hline Constructs & TAN & INT & SEA & EXP & CRE \\
\hline 1. Tangible (TAN) &. $\mathbf{8 3}$ & & & & \\
2. Intangible (INT) & $-.48^{* * *}$ & .85 & & & \\
3. Search (SEA) & $.29^{* * *}$ & $.31^{* * *}$ & $\mathbf{. 8 2}$ & & \\
4. Experience (EXP) & $.34^{* * *}$ & $.23^{* *}$ & $-.36^{* * *}$ & $\mathbf{8 0}$ & \\
5. Credence (CRE) & $.11^{*}$ & $.43^{* * *}$ & $-.39^{* * *}$ & $-.42^{* * *}$ & $\mathbf{. 8 1}$ \\
Average Variance Extracted (AVE) &. $\mathbf{6 2}$ & $\mathbf{. 6 6}$ & $\mathbf{. 6 1}$ & $\mathbf{. 5 9}$ & $\mathbf{. 5 6}$ \\
\hline
\end{tabular}

STUDY 1

\begin{tabular}{lcc}
\hline Constructs & PR & LIB \\
\hline 1. Perceived Risk (PR) & .84 & \\
2. Likelihood of Impulse Buying (LIB) & $-.45^{* * *}$ & $\mathbf{. 8 6}$ \\
Average Variance Extracted (AVE) &. $\mathbf{6 2}$ & $\mathbf{. 6 6}$ \\
\hline
\end{tabular}

STUDY 2

\begin{tabular}{lccccc}
\hline Constructs & CI & OSL & SM & PR & IB \\
\hline 1. Consumer Impulsiveness (CI) &. $\mathbf{8 2}$ & & & & \\
2. Optimum Stimulation Level (OSL) & $.25^{* *}$ & .85 & & & \\
3. Self-monitoring (SM) & -.05 & -.03 & .84 & & \\
4. Level of Perceived Risk (PR) & $-.31^{* * *}$ & $-.25^{* *}$ & $.29^{* *}$ & $\mathbf{. 8 8}$ & \\
5. Level of Impulsiveness (IB) & $.24^{* *}$ & $.18^{* *}$ & $-.16^{* *}$ & $-.48^{* * *}$ & $\mathbf{. 8 0}$ \\
Average Variance Extracted (AVE) & $\mathbf{. 5 9}$ & $\mathbf{. 6 5}$ & $\mathbf{. 6 2}$ & $\mathbf{. 6 6}$ & $\mathbf{. 6 2}$ \\
\hline
\end{tabular}

Note: Figures on diagonals represent composite reliabilities for each scale ${ }^{*} p<.05,{ }^{* *} p<.01,{ }^{* * *} p<.001$ (two-tailed) 
Table 4: Services Classification (Pretest)

\begin{tabular}{|c|c|c|c|c|c|}
\hline Service & Tangible & Intangible & Search & Experience & Credence \\
\hline Air travel & $\mathrm{H}(5.73 * * *)$ & $\mathrm{L}(4.38)$ & $\mathrm{L}(2.37)$ & $\mathrm{H}(4.41 * * *)$ & $\mathrm{L}(2.66)$ \\
\hline Bank account & $\mathrm{H}(5.62 * * *)$ & L (4.29) & $\mathrm{H}(4.51 * * *)$ & $\mathrm{L}(2.12)$ & $\mathrm{L}(2.43)$ \\
\hline Courier delivery & $\mathrm{H}(5.32 * *)$ & L (4.43) & $\mathrm{H}(4.62 * * *)$ & $\mathrm{L}(2.23)$ & $\mathrm{L}(2.37)$ \\
\hline Dress design & $\mathrm{H}\left(5.89^{* * *}\right)$ & $\mathrm{L}(4.11)$ & $\mathrm{H}\left(4.75^{* * *}\right)$ & $\mathrm{L}(2.87)$ & $\mathrm{L}(2.45)$ \\
\hline Driving lessons & $\mathrm{H}(5.74 * * *)$ & $\mathrm{L}(4.88)$ & $\mathrm{L}(2.28)$ & $\mathrm{L}(2.64)$ & $\mathrm{H}\left(4.51^{* * *}\right)$ \\
\hline Fast food restaurant & $\mathrm{H}(5.91 * * *)$ & L (4.39) & $\mathrm{H}\left(4.59^{* * *}\right)$ & $\mathrm{L}(2.18)$ & $\mathrm{L}(1.77)$ \\
\hline Fitness gym & $\mathrm{H}(6.23 * * *)$ & $\mathrm{L}(4.84)$ & $\mathrm{L}(2.26)$ & $\mathrm{L}(2.27)$ & $\mathrm{H}\left(4.75^{* * *}\right)$ \\
\hline Foot-massage & $\mathrm{H}\left(5.55^{* *}\right)$ & $\mathrm{L}(4.72)$ & $\mathrm{L}(2.34)$ & $\mathrm{H}(4.33 * * *)$ & $\mathrm{L}(2.46)$ \\
\hline Hair salon & $\mathrm{H}(5.42 * *)$ & L (4.67) & $\mathrm{L}(2.19)$ & $\mathrm{H}(4.42 * * *)$ & $\mathrm{L}(2.34)$ \\
\hline Hotel stay & $\mathrm{H}\left(5.67^{*}\right)$ & $\mathrm{L}(5.03)$ & $\mathrm{L}(2.45)$ & $\mathrm{H}\left(4.56^{* * *}\right)$ & $\mathrm{L}(2.29)$ \\
\hline Public transport & $\mathrm{H}(6.29 * * *)$ & L (4.89) & $\mathrm{L}(2.36)$ & $\mathrm{H}(4.67 * * *)$ & $\mathrm{L}(1.76)$ \\
\hline Suit tailoring & $\mathrm{H}\left(6.11^{* * *}\right)$ & $\mathrm{L}(4.95)$ & $\mathrm{H}\left(5.46^{* * *}\right)$ & $\mathrm{L}(2.43)$ & $\mathrm{L}(2.21)$ \\
\hline Tooth extraction & $\mathrm{H}(5.84 * * *)$ & L (4.79) & $\mathrm{L}(2.24)$ & $\mathrm{H}(4.78 * * *)$ & L (2.49) \\
\hline Live sports telecast & $\mathrm{H}(5.97 * * *)$ & $\mathrm{L}(4.33)$ & $\mathrm{L}(2.36)$ & $\mathrm{H}(4.27 * * *)$ & $\mathrm{L}(2.67)$ \\
\hline X-ray & $\mathrm{H}(5.34 * * *)$ & $\mathrm{L}(3.78)$ & $\mathrm{L}(2.11)$ & $\mathrm{L}(1.66)$ & $\mathrm{H}(4.83 * * *)$ \\
\hline Beauty care & $\mathrm{L}(4.87)$ & $\mathrm{H}(6.32 * * *)$ & $\mathrm{L}(2.39)$ & $\mathrm{L}(3.03)$ & $\mathrm{H}(4.72 * * *)$ \\
\hline Career advice & L (3.66) & $\mathrm{H}\left(5.84^{* * *}\right)$ & $\mathrm{L}(2.42)$ & $\mathrm{L}(2.11)$ & $\mathrm{H}(4.58 * * *)$ \\
\hline College education & $\mathrm{L}(3.73)$ & $\mathrm{H}(5.37 * * *)$ & $\mathrm{L}(3.33)$ & $\mathrm{H}(3.88 * *)$ & $\mathrm{L}(3.24)$ \\
\hline Credit card & $\mathrm{L}(3.29)$ & $\mathrm{H}(5.38 * * *)$ & $\mathrm{H}(4.77 * * *)$ & $\mathrm{L}(3.18)$ & $\mathrm{L}(3.37)$ \\
\hline Financial planning & $\mathrm{L}(3.81)$ & $\mathrm{H}\left(6.24^{* * *}\right)$ & $\mathrm{L}(2.83)$ & $\mathrm{L}(2.23)$ & $\mathrm{H}(4.99 * * *)$ \\
\hline Holiday package & L (4.93) & $\mathrm{H}\left(5.81^{* *}\right)$ & L (3.39) & $\mathrm{H}(4.79 * * *)$ & $\mathrm{L}(2.19)$ \\
\hline Insurance & $\mathrm{L}(4.38)$ & $\mathrm{H}(6.44 * * *)$ & $\mathrm{L}(4.38 * * *)$ & $\mathrm{L}(2.34)$ & $\mathrm{H}(5.02)$ \\
\hline Legal advice & $\mathrm{L}(3.92)$ & $\mathrm{H}(6.39 * * *)$ & $\mathrm{L}(2.27)$ & $\mathrm{L}(3.38)$ & $\mathrm{H}(4.91 * * *)$ \\
\hline Medical check-up & $\mathrm{L}(4.68)$ & $\mathrm{H}(5.77 * *)$ & $\mathrm{H}\left(4.36^{* * *}\right)$ & $\mathrm{L}(3.27)$ & $\mathrm{L}(2.44)$ \\
\hline Mobile phone plan & $\mathrm{L}(2.96)$ & $\mathrm{H}(5.32 * * *)$ & $\mathrm{H}\left(4.55^{* * *}\right)$ & $\mathrm{L}(3.32)$ & $\mathrm{L}(2.62)$ \\
\hline Movie theater & $\mathrm{L}(4.39)$ & $\mathrm{H}\left(5.76^{* * *}\right)$ & $\mathrm{H}(4.17 * * *)$ & $\mathrm{L}(2.86)$ & $\mathrm{L}(2.31)$ \\
\hline Music show & L (4.44) & $\mathrm{H}\left(6.23^{* * *}\right)$ & $\mathrm{L}(2.33)$ & $\mathrm{L}(2.78)$ & $\mathrm{H}(4.78 * * *)$ \\
\hline Nail painting & $\mathrm{L}(4.12)$ & $\mathrm{H}(5.67 * * *)$ & $\mathrm{H}(4.39 * * *)$ & $\mathrm{L}(2.47)$ & $\mathrm{L}(2.63)$ \\
\hline Night-club & $\mathrm{L}(4.67)$ & $\mathrm{H}\left(6.11^{* * *}\right)$ & $\mathrm{L}(1.84)$ & $\mathrm{H}(4.74 * * *)$ & $\mathrm{L}(2.45)$ \\
\hline Weight-loss program & $\mathrm{L}(2.67)$ & $\mathrm{H}(6.33 * * *)$ & $\mathrm{L}(1.79)$ & $\mathrm{L}(2.73)$ & $\mathrm{H}(5.11 * * *)$ \\
\hline Low - Nos. (Avg. Score) & $15(3.99)$ & $15(4.56)$ & $20(2.49)$ & $20(2.60)$ & $20(2.46)$ \\
\hline High - Nos. (Avg. Score) & $15(5.77)$ & $15(5.96)$ & $10(4.61)$ & $10(4.48)$ & $10(4.82)$ \\
\hline Total - Nos. (Avg. Score) & $30(4.88)$ & $30(5.26)$ & $30(3.55)$ & $30(3.54)$ & $30(3.64)$ \\
\hline
\end{tabular}

Note: $(\mathrm{L}=$ Low score, $\mathrm{H}=$ High score). Figures in brackets show the average score for each service on the respective characteristics and those with $*$ against them show a significantly higher score compared to the score for the other attribute/properties $(* \mathrm{p}<.05, * * \mathrm{p}<.01, * * * \mathrm{P}<.001)$ 
Table 5: Confirmatory Factor Analysis (Study 1)

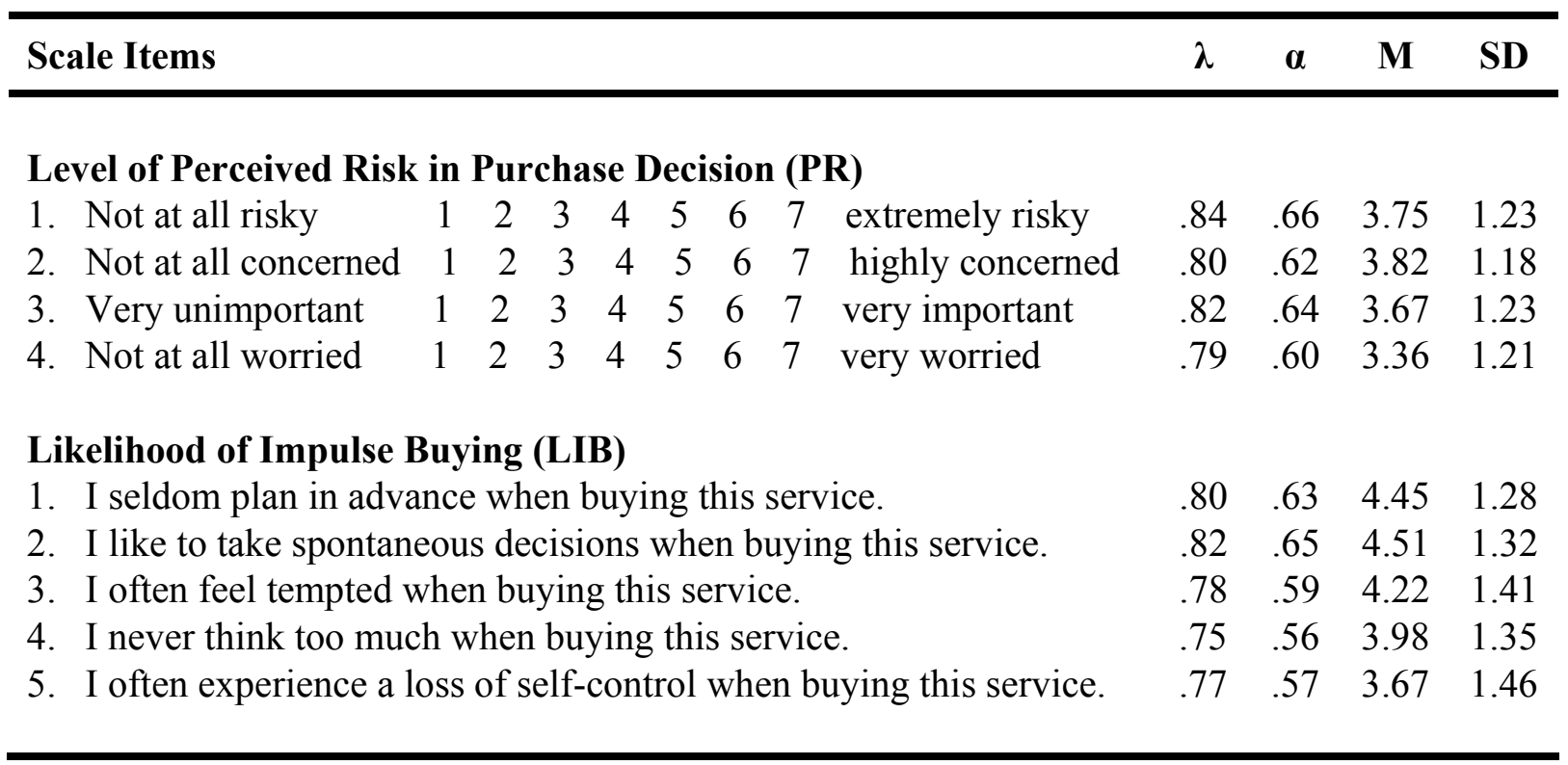

$\lambda$ : Factor loadings, $\alpha$ : Item-to-Total Correlations; M: Mean, $\mathrm{SD}=$ Standard Deviation 
Table 6: MANOVA Results (Study 1)

\begin{tabular}{|c|c|c|c|c|}
\hline & $\begin{array}{l}\text { Search } \\
\text { (SEA) }\end{array}$ & $\begin{array}{c}\text { Experience } \\
\text { (EXP) }\end{array}$ & $\begin{array}{l}\text { Credence } \\
\text { (CRE) }\end{array}$ & Total \\
\hline & \multicolumn{4}{|c|}{$\underline{\text { DV }=\text { Perceived Risk }(\mathbf{P R})}$} \\
\hline Tangible (TAN) & 1.68 & 3.37 & 4.51 & 3.03 \\
\hline Intangible (INT) & 2.85 & 4.23 & 5.29 & 4.26 \\
\hline \multirow[t]{2}{*}{ Total } & 2.27 & 3.63 & 5.06 & 3.65 \\
\hline & \multicolumn{4}{|c|}{$\underline{\text { DV }=\text { Likelihood of Impulse Buying (LIB) }}$} \\
\hline Tangible (TAN) & 6.07 & 4.90 & 3.33 & 4.98 \\
\hline Intangible (INT) & 4.85 & 3.73 & 2.14 & 3.36 \\
\hline Total & 5.46 & 4.55 & 2.50 & 4.17 \\
\hline \multicolumn{2}{|c|}{ H1: (a) PR (TAN) < PR (INT) } & \multicolumn{3}{|c|}{$3.03-4.26=-1.23, p<.001$, Supported } \\
\hline \multicolumn{2}{|c|}{ (b) LIB (TAN) > LIB (INT) } & \multicolumn{3}{|c|}{$4.98-3.36=1.62 . \mathrm{p}<.001$, Supported } \\
\hline \multicolumn{2}{|c|}{ H2a: (i) PR (SEA) < PR (EXP) } & \multicolumn{3}{|c|}{$2.27-3.63=-1.36, \mathrm{p}<.001$, Supported } \\
\hline \multicolumn{2}{|c|}{ (ii) LIB (SEA) > LIB (EXP) } & \multicolumn{3}{|c|}{$5.46-4.55=0.91, \mathrm{p}<.001$, Supported } \\
\hline \multicolumn{2}{|c|}{ H2b: (i) PR (EXP) < PR (CRE) } & \multicolumn{3}{|c|}{$3.63-5.06=-1.43, p<.001$, Supported } \\
\hline \multicolumn{2}{|c|}{ (ii) LIB (EXP) $>$ LIB (CRE) } & \multicolumn{3}{|c|}{$4.55-2.50=1.95, \mathrm{p}<.001$, Supported } \\
\hline
\end{tabular}


Table 7 - Hypotheses Summary (Study 2)

\begin{tabular}{|c|c|c|c|c|c|c|}
\hline $\begin{array}{l}\text { Hypothesized } \\
\text { Relationship }\end{array}$ & $\frac{\text { Overall }}{\text { (a) }}$ & $\underline{\text { Tangible }}$ & $\underline{\text { Intangible }}$ & $\underline{\text { Search }}$ & (c) & $\underline{\text { Credence }}$ \\
\hline H3: CI $\rightarrow$ PR & - & --- & - & --- & -- & - \\
\hline H4: OSL $\rightarrow$ PR & - & --- & - & --- & -- & - \\
\hline H5: SM $\rightarrow$ PR & + & + & +++ & + & ++ & +++ \\
\hline H6(i): SM X CI $\rightarrow$ PR & - & - & --- & - & -- & --- \\
\hline H6(ii): SM X OSL $\rightarrow$ PR & - & - & --- & - & -- & --- \\
\hline H7: PR $\rightarrow$ IB & - & - & - & - & - & - \\
\hline
\end{tabular}

Note: The number of '-' or '+' signs denotes the relative strengths of hypothesized relationship.

Table 8 - Services Classification (Study 2)

\begin{tabular}{lccc}
\hline & Search & Experience & Credence \\
\hline \multirow{2}{*}{ Tangible } & $\begin{array}{c}\text { Fast Food } \\
\text { Restaurant }\end{array}$ & Hair Salon & $\begin{array}{c}\text { Fitness } \\
\text { Club }\end{array}$ \\
& & & \\
Intangible & Movie & Theme & $\begin{array}{c}\text { College } \\
\text { Theater }\end{array}$ \\
& Park & Education \\
\hline
\end{tabular}


Table 9 - Confirmatory Factor Analysis (Study 2)

\begin{tabular}{|c|c|c|c|c|}
\hline Scale Items & $\lambda$ & $\alpha$ & $\mathbf{M}$ & SD \\
\hline $\begin{array}{l}\text { Consumer Impulsiveness (CI) } \\
\text { To what extent do you agree that the following statements describe you? } \\
\text { 1. I often spend more than what I can afford } \\
\text { 2. I like to indulge myself by buying things for pleasure } \\
\text { 3. I lose self-control quite frequently } \\
\text { 4. I often act without thinking about the consequences } \\
\text { 5. I seldom plan anything in advance } \\
6 \text {. I often make decisions spontaneously }\end{array}$ & $\begin{array}{l}.77 \\
.81 \\
.79 \\
.75 \\
.72 \\
.78\end{array}$ & $\begin{array}{l}.56 \\
.62 \\
.60 \\
.53 \\
.50 \\
.58\end{array}$ & $\begin{array}{l}4.23 \\
4.43 \\
4.25 \\
4.40 \\
4.17 \\
4.22\end{array}$ & $\begin{array}{l}1.36 \\
1.51 \\
1.60 \\
1.23 \\
1.32 \\
1.25\end{array}$ \\
\hline $\begin{array}{l}\text { Optimum Stimulation Level (OSL) } \\
\text { To what extent do you agree that the following statements describe you? } \\
\text { 1. I like to experience novelty and change in daily routine } \\
\text { 2. I am continually seeking new ideas and experiences } \\
\text { 3. I like continually changing activities } \\
\text { 4. When things get boring, I like to try something different }\end{array}$ & $\begin{array}{l}.80 \\
.82 \\
.79 \\
.81\end{array}$ & $\begin{array}{l}.58 \\
.61 \\
.56 \\
.60\end{array}$ & $\begin{array}{l}4.67 \\
4.56 \\
4.36 \\
4.23\end{array}$ & $\begin{array}{l}1.32 \\
1.27 \\
1.43 \\
1.34\end{array}$ \\
\hline $\begin{array}{l}\text { Self-monitoring (SM) } \\
\text { To what extent do you agree that the following statements describe you? } \\
\text { 1. In social situations, I have the ability to alter my behavior if I feel that something else is called for } \\
\text { 2. I can control the way I come across to people, depending on the impression I wish to give them } \\
\text { 3. When I feel that the image I am portraying isn't working, I can readily change it to something that does } \\
\text { 4. I have found that I can adjust my behavior to meet the requirements of any situations I find myself in } \\
\text { 5. Once I know what the situation calls for, it's easy for me to regulate my actions accordingly }\end{array}$ & $\begin{array}{l}.77 \\
.78 \\
.82 \\
.80 \\
.75\end{array}$ & $\begin{array}{l}.56 \\
.57 \\
.62 \\
.61 \\
.52\end{array}$ & $\begin{array}{l}3.91 \\
3.67 \\
3.83 \\
3.74 \\
3.65\end{array}$ & $\begin{array}{l}1.35 \\
1.27 \\
1.24 \\
1.38 \\
1.29\end{array}$ \\
\hline 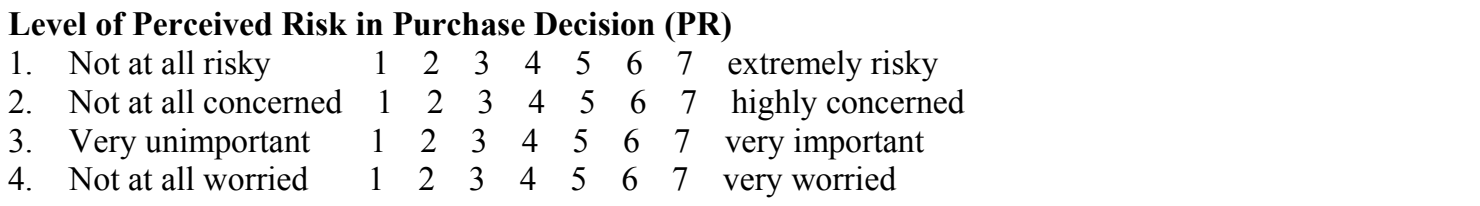 & $\begin{array}{l}.84 \\
.82 \\
.81 \\
.78\end{array}$ & $\begin{array}{l}.63 \\
.61 \\
.60 \\
.58\end{array}$ & $\begin{array}{l}3.35 \\
3.46 \\
3.34 \\
3.22\end{array}$ & $\begin{array}{l}1.26 \\
1.31 \\
1.27 \\
1.56\end{array}$ \\
\hline $\begin{array}{l}\text { Level of Impulsiveness in Purchase Decision (IB) } \\
\text { To what extent do you agree with the following statements about your decision to choose (name of service)? } \\
\text { 1. I did not even think about choosing the (name of service) } \\
\text { 2. I thought about choosing the (name of service) but decided not to do it* } \\
\text { 3. I was tempted to choose the (name of service) } \\
\text { 4. I did not even consider the consequences of choosing the (name of service) } \\
\text { 5. I chose the (name of service) as quickly as possible, before I changed my mind }\end{array}$ & $\begin{array}{l}.78 \\
.77 \\
.82 \\
.80 \\
.75\end{array}$ & $\begin{array}{l}.57 \\
.56 \\
.61 \\
.59 \\
.53\end{array}$ & $\begin{array}{l}3.89 \\
3.63 \\
3.71 \\
3.56 \\
3.64\end{array}$ & $\begin{array}{l}1.53 \\
1.62 \\
1.41 \\
1.43 \\
1.78\end{array}$ \\
\hline
\end{tabular}

$\lambda$ : Factor loadings, $\alpha$ : Item-to-Total Correlations; M: Mean, SD = Standard Deviation; * Reverse-scored items 
Table 10 - Multi-group Moderator Analysis (Study 2)

\begin{tabular}{l|c|cc|cc|c}
\hline Hypotheses & $\begin{array}{c}\text { Overall } \\
\text { (a) }\end{array}$ & Tangible & Intangible & $\chi_{(413)}^{2}$ & $\Delta \chi_{(\mathbf{d d f}=\mathbf{1})}^{2}$ & Result \\
\hline H3: CI $\rightarrow$ PR & -.24 & -.31 & -.14 & 672.65 & $13.86^{* * *}$ & Supported \\
H4: OSL $\rightarrow$ PR & -.21 & -.25 & -.15 & 669.24 & $10.45^{* * *}$ & Supported \\
H5: SM $\rightarrow$ PR & .35 & .27 &. $\mathbf{4 4}$ & 667.41 & $8.62^{* *}$ & Supported \\
H6(i): SM X CI $\rightarrow$ PR & -.22 & -.18 & -.25 & 666.17 & $7.38^{* *}$ & Supported \\
H6(ii): SM X OSL $\rightarrow$ PR & -.19 & -.16 & -.23 & 664.76 & $5.97^{*}$ & Supported \\
H7: PR $\rightarrow$ IB & -.32 & -.24 & -.34 & NA & NA & Supported \\
\hline
\end{tabular}

\begin{tabular}{|c|c|c|c|c|c|}
\hline \multicolumn{6}{|c|}{$\left(\right.$ Overall $\left.\chi_{(412)}^{2}=448.63\right)$} \\
\hline Hypotheses & Search & Experience & $\chi_{(413)}^{2}$ & $\Delta \chi_{(\Delta d f=1)}^{2}$ & Result \\
\hline $\mathrm{H} 3 \mathrm{c}: \mathrm{CI} \rightarrow \mathrm{PR}$ & -.27 & -.21 & 453.57 & $4.94^{*}$ & Supported \\
\hline $\mathrm{H} 4 \mathrm{c}: \mathrm{OSL} \rightarrow \mathrm{PR}$ & -.29 & -.23 & 453.14 & $4.51^{*}$ & Supported \\
\hline $\mathrm{H} 5 \mathrm{c}: \mathrm{SM} \rightarrow \mathrm{PR}$ & .29 & .34 & 451.92 & 3.29 & Not supported \\
\hline H6c(i): SM X CI $\rightarrow$ PR & -.17 & -.25 & 456.09 & $7.43^{* *}$ & Supported \\
\hline H6c(ii): SM X OSL $\rightarrow$ PR & -.15 & -.22 & 454.27 & $5.64^{*}$ & Supported \\
\hline $\mathrm{H} 7: \mathrm{PR} \rightarrow \mathrm{IB}$ & -.24 & -.29 & NA & NA & Supported \\
\hline
\end{tabular}

$\left(\right.$ Overall $\left.\chi_{(412)}^{2}=472.38\right)$

\begin{tabular}{l|cc|cc|c}
\hline Hypotheses & Experience & Credence & $\chi_{(413)}^{2}$ & $\Delta \chi_{(\Delta d f=1)}^{2}$ & Result \\
\hline H3d: CI $\rightarrow$ PR & -.21 & -.12 & 481.66 & $9.28^{* *}$ & Supported \\
H4d: OSL $\rightarrow$ PR & -.23 & -.15 & 480.79 & $8.41^{* *}$ & Supported \\
H5d: SM $\rightarrow$ PR & .34 & $\mathbf{. 4 2}$ & 481.21 & $8.83^{* *}$ & Supported \\
H6d(i): SM X CI $\rightarrow$ PR & -.25 &.- .32 & 479.34 & $6.96^{* *}$ & Supported \\
H6d(ii): SM X OSL $\rightarrow$ PR & -.22 &.- .31 & 483.73 & $11.35^{* * *}$ & Supported \\
H7: PR $\rightarrow$ IB & -.29 & -.36 & NA & NA & Supported \\
\hline
\end{tabular}

